\title{
Mast cells in leprosy skin lesions
}

\author{
VIJAYA V. MYSOREKAR, \\ CHITRALEKHA P. DANDEKAR \& SARASWATI G. RAO \\ Department of Pathology, M. S. Ramaiah Medical College, \\ Bangalore, India
}

\section{Accepted for publication 8 October 2000}

Summary The density and distribution of mast cells was assessed in skin biopsies of 118 untreated leprosy cases and 20 healthy individuals taken as controls. Mast cells were present in only small numbers in the skin biopsies of healthy individuals. Significantly higher mast cell counts were obtained in the skin lesions of indeterminate leprosy $(P<0.01)$. The mast cell count in the tuberculoid group was significantly lower than that in the lepromatous group $(P<0.05)$. The lepromatous group also showed increased mast cell degranulation and altered morphology. The mast cell distribution in the skin biopsies of the two groups was, however, similar. The mast cell count in leprosy is probably determined by the pattern of cytokines released by the $\mathrm{T}$ lymphocytes. However, the influence of mast cells on the outcome of the disease needs to be evaluated further.

\section{Introduction}

In leprosy, the level of the host cellular immune response to Mycobacterium leprae determines the pattern of the disease, thus giving rise to a spectrum of clinical and histopathological features. ${ }^{1,2}$ Mast cells have not received much attention in leprosy, but evidence linking them with the development of delayed hypersensitivity reactions ${ }^{3}$ raises the possibility that they might be of some significance in leprosy lesions.

The aim of the present study was to assess the density and distribution of mast cells and their possible role in the skin lesions of leprosy.

\section{Materials and methods}

The present study was conducted on 118 untreated leprosy patients visiting the Dermatology department of M. S. Ramaiah Medical Teaching Hospital, Bangalore, India. The cases

Correspondence to: V. V. Mysorekar, 55-55A, A.E.C.S. Layout, $60 \mathrm{ftrd}$, behind ISRO, R.M.V. Extension Stage 11, Bangalore 560 094, India (e-mail: dandekar@bgl.vsnl.net.in) 
included 64 males and 54 females ranging in age from 7 to 82 years. In each case, a $4 \mathrm{~mm}$ punch biopsy specimen was obtained from the skin lesion, under local anaesthesia with $1 \%$ lignocaine. Biopsies taken from the normal skin of 20 healthy individuals undergoing surgery for trauma, served as controls.

Each biopsy was fixed in $10 \%$ buffered formalin and sent to the Department of Pathology, M. S. Ramaiah Medical College, Bangalore, India, for processing in the conventional manner. From each skin biopsy, serial paraffin sections of 5 micron thickness were cut and stained with haematoxylin and eosin $(\mathrm{H} \& \mathrm{E})$, Fite-Faraco stain for acid-fast bacilli and $1 \%$ aqueous toluidine blue for mast cells.

The H \& E and Fite-Faraco stained sections were studied and the leprosy cases were classified into five groups: lepromatous leprosy (LL), borderline lepromatous leprosy (BL), mid-borderline leprosy (BB), borderline tuberculoid leprosy (BT) and tuberculoid leprosy (TT). ${ }^{1,2}$ Cases where there were one or two small hypopigmented macules on the skin with a slight sensory impairment clinically, and where the skin biopsy histologically showed a nonspecific lymphocytic infiltration around dermal nerve twigs with occasional acid-fast bacilli, were labelled as indeterminate leprosy. The toluidine blue stained sections were studied for the density and distribution of mast cells. The mast cell counts were performed using a light microscope at $\times 400$ magnification. The average counts obtained in 20 non-overlapping high power fields (HPFs) were considered in each case.

The density of mast cells was expressed as the number of cells per $\mathrm{mm}^{2}$. The histopathological diagnoses and mast cell counts in all the cases were done independently by all the three authors.

\section{Results}

Out of the 118 leprosy cases in the present study, there were $18 \mathrm{LL}, 20 \mathrm{BL}, 14 \mathrm{BB}, 20 \mathrm{BT}$ and 21 TT cases. The remaining 25 cases were diagnosed as indeterminate leprosy. Four of the 18 cases of LL had features of histoid leprosy.

The mean density of mast cells in the 20 control skin biopsies was 12.6 per $\mathrm{mm}^{2}$. The density of mast cells in the skin lesions in the 118 leprosy cases is given in Table 1 . When the results were statistically analysed by using the 'analysis of variance' method, it was found

Table 1. Density of mast cells in the skin lesions of the various types of leprosy

\begin{tabular}{lccc}
\hline & & \multicolumn{2}{c}{ Mast cell density per $\mathrm{mm}^{2}$} \\
\cline { 3 - 4 } Type of leprosy & Number of cases & Mean & Standard deviation (SD) \\
\hline LL & 18 & $115 \cdot 3$ & $45 \cdot 6$ \\
BL & 20 & $104 \cdot 3$ & $32 \cdot 2$ \\
BB & 14 & $68 \cdot 3$ & $38 \cdot 9$ \\
BT & 20 & $23 \cdot 4$ & $24 \cdot 9$ \\
TT & 21 & $15 \cdot 8$ & $20 \cdot 5$ \\
Indeterminate & 25 & $109 \cdot 0$ & $33 \cdot 4$ \\
Total & 118 & - & - \\
Controls & 20 & $12 \cdot 6$ & $9 \cdot 4$ \\
\hline
\end{tabular}



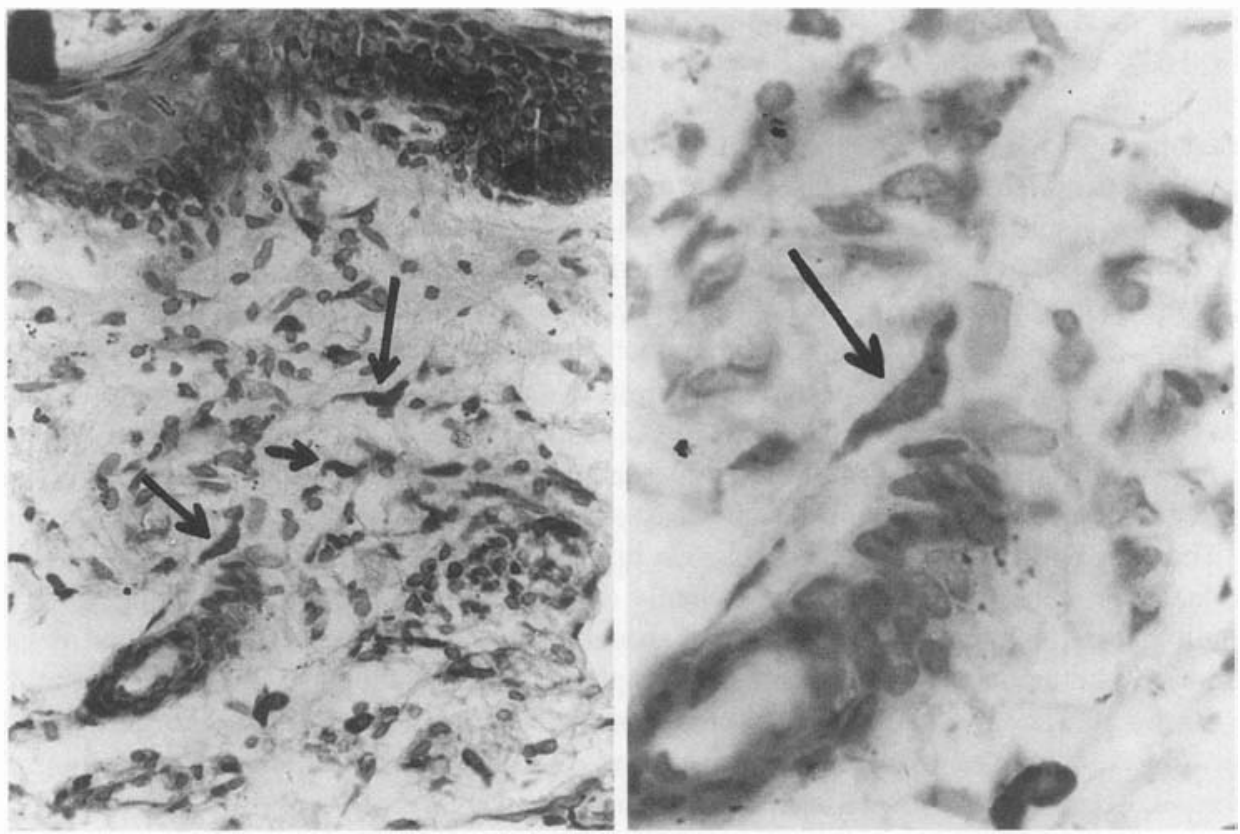

Figure 1. Lepromatous leprosy: subepidermal thin and elongated mast cells (arrows). (a) Toluidine blue $\times 320$; (b) toluidine blue $\times 800$.

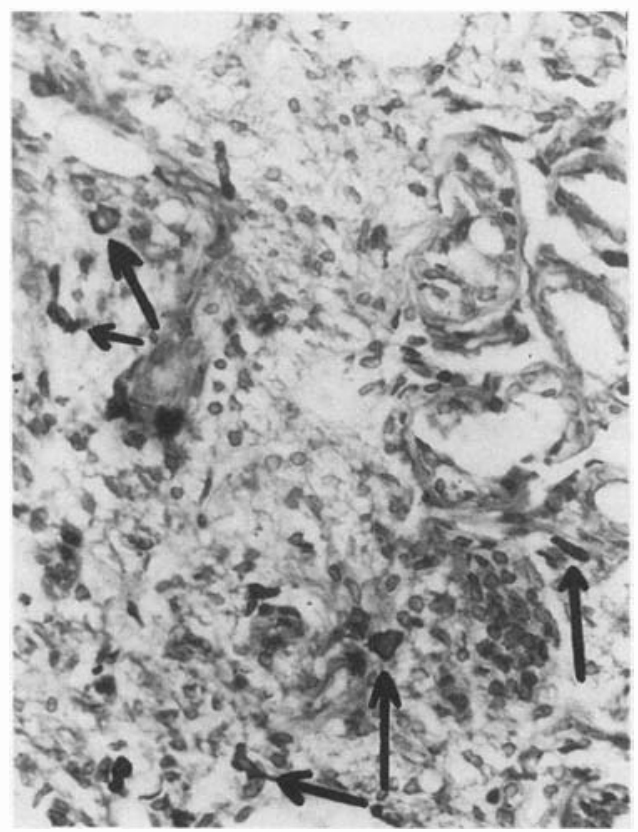

Figure 2. Lepromatous leprosy: mast cells (arrows) are seen amidst the foamy macrophages and around the sweat glands visible in the upper part. Toluidine blue $\times 320$. 
that the mast cell density was significantly higher in lesions of indeterminate leprosy $(P<0.01)$, LL $(P<0.01)$, BL $(P<0.01)$ and BB $(P<0.05)$ when compared with the controls. The mast cell density in lesions of BT and TT did not differ significantly from the controls $(P>0.05)$. As can be seen from Table 1, the mast cell density was found to be decreasing from the lepromatous to the tuberculoid end of the spectrum. There was no statistically significant difference between the mast cell density in LL and BL biopsies $(P>0.05)$. Similarly, there was also no statistically significant difference between the mast cell density in BT and TT biopsies $(P>0.05)$. Among the two basic groups, tuberculoid (including $21 \mathrm{TT}$ and $20 \mathrm{BT}$ ) and lepromatous (including $18 \mathrm{LL}$ and $20 \mathrm{BL}$ ), the mast cell density in the first group was found to be significantly lower than that in the second group $(P<0.05)$. Three of the 20 BT biopsies $(15.0 \%)$ and 10 of the 21 TT biopsies $(47.6 \%)$ studied did not show any mast cells in the sections scanned for these cells. Histoid leprosy biopsies showed mast cell counts similar to other cases of the lepromatous group.

The distribution of mast cells in the skin biopsies of the two groups of leprosy cases was similar. Mast cells were seen subepidermally (Figure 1), in the centre and periphery of the granuloma, in the intervening dermis, and around skin appendages (Figure 2), blood vessels and nerves. In the majority of the cases, macrophages and lymphocytes were seen adjacent to the mast cells. The mast cells in the skin biopsies of LL cases showed altered morphology, appearing thin and elongated (Figure 1) and in different stages of degranulation. An occasional case of LL showed mast cells even in the deeper fat.

\section{Discussion}

The shape of the mast cell seems to correspond with its dynamic functional state when fixed. ${ }^{4}$ Round to oval mast cells are seen in the normal dermis but following a stimulus, the cell changes its shape and elongates to discharge the granules. Thus, a high mast cell count with mast cell elongation and extensive degranulation in LL indicates their greater functional activity in these lesions. ${ }^{5}$

A predominance of mast cells in the lepromatous group as compared to the tuberculoid group has been described by other authors also, ${ }^{6,7}$ although their counts are not quantitative. The present study did not show any difference between the mast cell numbers in histoid leprosy skin biopsies and those from other cases of the lepromatous group, as has also been noted by others. ${ }^{7}$

Mast cells are activated by cytokines including interleukin-3 (IL-3), IL-4 and granulocyte-macrophage colony-stimulating factor (GM-CSF) derived from the T lymphocytes, of which IL-4 is the most essential. ${ }^{8}$ The difference in the mast cell counts in the lepromatous and tuberculoid groups has been explained on the basis of the difference in the cytokine patterns and T cell subsets in the two groups. ${ }^{9,10}$ In lepromatous lesions, the activated CD 4+ helper $\mathrm{T}$ cells of $\mathrm{T}_{\mathrm{H}} 2$ type produce high levels of IL-4, which in turn activates the mast cells. ${ }^{9}$ On the other hand, in tuberculoid leprosy, the $C D 4+$ helper $T$ cells are of the $T_{H} 1$ type. These cells produce undetectable levels of IL-4, ${ }^{10}$ thus accounting for the low mast cell response in tuberculoid leprosy. It has been stated that a reduction of mast cells may occur only if the lepromatous lesions upgrade to become more of the tuberculoid type, with changes in the cytokine pattern. ${ }^{11}$

Aroni et $a l^{7}$ suggest that the larger number of mast cells in the lepromatous group as compared to the tuberculoid group may be linked to the increased vascularity and changes 
observed in the endothelial cells which are more obvious in lepromatous leprosy. Mast cell mediators like histamine, heparin and a tumour necrosis factor $\alpha$ (TNF- $\alpha$ )-like molecule are known to be mitogenic for fibroblasts and endothelial cells. ${ }^{12}$ Thus, mast cells may also play a role in fibroblastic proliferation following reactive episodes in leprosy. ${ }^{6}$

Cree et al. ${ }^{13}$ in their study, found that the granuloma mast cell density was decreased in multibacillary patients as compared to paucibacillary patients. They explain that this might be an apparent decrease due to the increase in dermal volume as a result of oedema in multibacillary patients.

A similar pattern of mast cell distribution has been found in the skin biopsies of the lepromatous and tuberculoid leprosy groups in the present study as well as in other studies. ${ }^{7,13}$ It has been suggested that the mast cells in the Grenz zone in LL cases might be related to various cytokines released from the keratinocytes. ${ }^{14}$

A high mast cell count in indeterminate leprosy biopsies was a striking feature in the present study. This observation has been reported by other authors also. ${ }^{6,15}$ Thus, it is likely that a mast cell response occurs in the initial stages of evolution of leprosy. ${ }^{6}$ Hence, we feel that a mast cell count on skin biopsies may be of diagnostic value in indeterminate leprosy.

It would have been interesting to know the effect of anti-leprosy treatment on the mast cell counts in the skin lesions in the present cases. However, unfortunately, such a follow-up study could not be conducted in our set-up for two reasons: 1) some patients do not follow strictly the prescribed drug regimen, and hence may show unreliable mast cell counts in follow-up biopsies, and 2) some patients do not come for follow-up as they have to travel from far off villages. However, we suggest that further studies on mast cells in treated leprosy patients would be worthwhile, as they would provide valuable information on the role of immunomodulatory drugs in determining the immune response related to mast cells.

In conclusion, the present study indicates that a prominent mast cell response occurs in the skin lesions of the lepromatous group and indeterminate leprosy. However, the exact significance of mast cell proliferation and degranulation in leprosy is not known. The point whether mediators from the mast cells have any influence on the outcome of the disease needs further evaluation.

\section{Acknowledgement}

We thank the Department of Dermatology, M. S. Ramaiah Medical Teaching Hospital, Bangalore, India, for providing the biopsy material for this study.

\section{References}

${ }^{1}$ Ridley DS, Jopling WH. Classification of leprosy according to immunity: a five group system. Int J Lepr, 1966; 34: 255-273.

2 Ridley DS. Histological classification and the immunological spectrum of leprosy. Bull WHO, 1974; 51: 451-465.

${ }^{3}$ Galli SJ, Dvorak AM. What do mast cells have to do with delayed hypersensitivity? Lab Invest, 1984; 50: 365368.

4 Kumar R. Vaidya MC, Keshwani NH. In vivo response of mast cells to lepromatous serum. Lepr India, 1979; 51: 49-53.

${ }^{5}$ Kumar R. Mast cells in histoid lepromatous lesions. Ind J Lepr, 1987; 59: 390-392.

${ }^{6}$ Rav SD, Pratap VK, Sharma NK, Dayal SS. Mast cell in leprosy. Ind J Lepr, 1990; 62: 467-472.

7 Aroni K, Kontochristopoulos G, Liossi A, Panteleos D. An investigation of mast cells in two basic leprosy groups. Int J Lepr, 1993; 61: 634-635. 
${ }^{8}$ Cotran RS, Kumar V, Collins T. Diseases of immunity. In: Robbins (ed) Pathologic basis of disease, $6^{\text {th }}$ edn. Saunders, Philadelphia, 1999, pp 188-259.

9 Yamamura M, Uyemura K, Deans RJ et al. Defining protective responses to pathogens: cytokine profiles in leprosy lesions. Science, 1991; 254: 277-279.

10 Haanen JBA, De Waal-Malefut R, Res PCM et al. Selection of a human T helper type l-like T cell subset by mycobacteria. J Exp Med, 1991; 174: 583-592.

11 Jayalakshmi P. Mast cells in lepromatous leprosy. Int J Lepr, 1995; 63: 291-293.

12 Rothe MJ, Kerdel FA. The mast cell in fibrosis. Int J Dermatol, 1991; 30: 13-16.

13 Cree IA, Coghill G, Swanson Beck J. Mast cells in leprosy skin lesions. J Clin Pathol, 1990; 43: 196-200.

${ }^{14}$ Kupper SK. Mechanisms of cutaneous inflammation. Arch Dermatol, 1989; 125: 1406-1412.

15 Liu Zijun et al. Histopathology of primary indeterminate leprosy. Chin J Dermatol, 1980; 13: 129 (abstracted in Int J Lepr, 1982; 50: 550). 